\title{
A Hybrid Body Technique: Does the Pulse Diagnostic cun guan chi Method Have Chinese- Tibetan Origins?
}

Elisabeth Hsu

\section{Summary}

This article investigates the medieval origins of the main pulse diagnostic method in contemporary Chinese medicine, sometimes known as san bu 三部 (three sectors) method, which requires physicians to examine the mai 脈 (vessels, vessel movements or pulse) on the wrist at the three locations cun guan chi 寸關尺 (inch, gate, foot). The article provides evidence to suggest that this body technique grew out of an earlier Chinese one, the cun chi 寸尺 (inchfoot) method, which appears to have aimed at investigating the qualities of yin and yang in order to determine the condition of a patient by means of exploring fairly large areas of the patient's body surface with the palms. The article furthermore posits that the cun chi method was decisively transformed in medieval times, presumably due to the impact of early Tibetan pulse diagnostic practices: it became framed in a numerology of three and started advocating the use of the fingertips for sensing the pulse beats. The article, which draws on detailed textual analyses of medieval manuscripts, on visual evidence and also on psychophysical research, furthermore highlights how misunderstandings can constructively contribute to cultural communication.

Keywords: Chinese medicine; Tibetan medicine; Dunhuang medical manuscripts; pulse diagnosis; body techniques; cun guan chi 寸關尺; san bu 三部; tactility

Dr Elisabeth Hsu, Institute of Social and Cultural Anthropology, University of Oxford, 51 Banbury Road, GB-Oxford OX2 6PE (elisabeth.hsu@anthro.ox.ac.uk). 
This article is concerned with medieval developments in the history of the main pulse diagnostic method in contemporary Chinese medicine ${ }^{1}$, which differentiates between the locations cun guan chi 寸關尺 (inch, gate, foot) on the wrist and in medieval times was also known as san bu 三部 (three sectors) method $^{2}$. This body technique requires physicians to learn to feel mai 脈 (vessels, vessel movements or pulse) at the three locations cun guan chi, by applying different degrees of pressure to the mai with three different fingers, the index, the middle and ring finger. It allows physicians to feel "pulse images" (mai xiang 脈象) which indicate the kinds of processes that are affecting the five internal viscera and an additional sixth internal body part. Thus, the pulse images felt at the cun position indicate the condition of the heart and lungs, those at the guan position that of the liver and spleen, and those at the chi position that of the two kidneys (or the kidneys and the "gate of life" or yet another variant) ${ }^{3}$.

In this article I argue that the contemporary cun guan chi method, as just outlined, was not known to the Chinese since time immemorial but dates to the medieval period. It had its precursors in closely related pulse diagnostic practices and has, no doubt, since been modified without, however, being transformed beyond recognition. Although the cun guan chi method is currently celebrated as distinctly Chinese, this article will point to aspects of possible Tibetan provenance and highlight hybridity. Without contradicting the scholarship that has demonstrated that Chinese pulse diagnostic rationale was transposed into Tibetan medicine $e^{4}$, this article explores the possibility as to whether, particularly at the level of hands-on interventions and body techniques, Tibetan practices transformed medieval Chinese ones. It needs to be kept in mind that the Dunhuang area, whence most of the textual material explored in this article comes, was a melting pot of transregional practices from the 6th to the 11th century $\mathrm{AD}$, and it is likely that Chinese and Tibetan medicine were practised side by side.

1 The term "pulse diagnostics" is used here in a wide sense and does not refer to the contemporary biomedical method of counting pulse beats only. In contexts relating to Chinese medicine it refers to the exploration of the mai 脈 (vessels, pulses) for diagnostic purposes, in the context of Tibetan, Ayurvedic and Galenic medicine its definition is less precise.

2 This article draws primarily the Dunhuang texts on the san bu method. Their identification and the numbering of the columns on the manuscripts follow Ma et al. (1998), that of thematic sections and subsections Hsu (forthcoming).

3 Deng 1984, 62-64. The Chinese medical viscera are culture-specific entities; see Sivin (1987) for their contemporary, Despeux (forthcoming) for their medieval and Hsu (in press) for their ancient interpretation.

4 E.g. Meyer 1990; Zhen/Cai 2007. 


\section{A note on methodology}

The argument put forth in this article relies mostly on manuscript evidence that can be dated, in the case of the Mawangdui and Zhangjiashan medical manuscripts to the mid-second century BC and in the case of the Dunhuang manuscripts to the 6-11th century $\mathrm{AD}^{5}$. It also draws on few textual excerpts from canonical medical compilations such as the Yellow Emperor's Inner Canon (Huangdi neijing 黃帝內經), the Canon of Sphygmology (Mai jing 脈經) and the Canon of Difficult Issues (Nan jing 難經), which due to their complicated textual histories, and the peculiar mode in which Chinese esoteric texts were transmitted, are notoriously difficult to date. They are here taken as texts compiled within the over one thousand year long time period from the Han (206 BC-220 AD) through the Tang (618-907 AD) to the Song dynasty (960-1229 AD) ${ }^{6}$.

Both the manuscript and received literature are read as containing compilations of texts from different medical lineages that record, in Kovacs and Unschuld's words ${ }^{7}$, "undecided controversies", and thus can and do juxtapose statements that are often incongruous and sometimes contradictory. Keegan's text-critical study furthermore highlighted that in esoteric fields like medicine ${ }^{8}$, which adopted a particular mode of transmitting knowledge, compilations (texts 2) may incorporate in a fairly unaltered fashion sections and paragraphs (texts 1) composed at an earlier date. In other words, the overall organisation of knowledge, the chapter titles and some interpolated connecting paragraphs may date to a later time period than the texts assembled in a compilation. This "modular reading" of texts is in what follows applied to both the manuscript and received literature.

Since texts describing body techniques are extremely limited and since there are no depictions of pulse diagnostic procedures in early and medieval China, the article furthermore takes recourse to indirect evidence. First, it

\footnotetext{
5 For transcription of the Mawangdui manuscripts on themes classified as medical, see Mawangdui Hanmu boshu zhengli xiaozu (1985). For translation of all those, see Harper 1998. For a freely edited and richly annotated version, see Ma 1992. For the Zhangjiashan manuscripts, see Zhangjiashan 247 hao Hanmu zhujian zhengli xiaozu (ZJS 2001). For transcriptions of texts on themes deemed medical in the Dunhuang manuscripts, and their division into sections, see Ma et al. 1998. See also Cong 1994. For a detailed description of this corpus, see Despeux (forthcoming).

6 For the textual history of the two books of the Huangdi neijing, called Su wen 素問 (Basic Questions) and Ling shu 靈樞 (Divine Pivot), and the Huangdi neijing Taisu 太素, which comprises the contents of both, often in a telling variant form, see Sivin 1993; for the Nan jing, see Unschuld 1986; for the Mai jing, see Ma 1990,144-149.

7 Kovacs/Unschuld 1998, 19.

8 Keegan 1988.
} 
asks what sort of bodily sensitivities a doctor had to develop when engaging in pulse diagnostics, which it indirectly deduces from the predominant conceptual frameworks of the early and medieval periods. Second, the argument is reinforced by evidence from modern scientific research on psychophysics to make plausible a finding derived from textual investigations combined with a question prompted by considerations pertaining to bodily experiences. Third, the study takes account of 17th century Tibetan thankas and 19th century Chinese illustrations. On the Chinese side, I would argue it is justifiable to do so because the basics of the cun guan chi method do not appear to have been substantially transformed since medieval times. Perhaps, this applies also to Tibetan medicine, although its history of diagnostics is not as well documented.

\section{The structure of the argument}

The article is divided into two parts with each three sections. The first part will establish the extent to which what I here call the "cun guan chi method" can be regarded a medieval innovation, the second will explore to what extent Tibetan practices may have instigated the observed change in body techniques. In part one, the first section presents the cun guan chi method in a medieval Dunhuang manuscript, and the third establishes what the medieval innovation was: it shows that some texts speak of a cun guan chi method where the cun-inch-area is one inch long and the chi-foot-area is one foot long, and the guan-gate-area, as the word would have it, is a boundary line between the two. Other texts speak of a cun guan chi method, where each of the three locations has the same size, each one inch long. They describe a situation where each of the three locations is equal in extent. Since the contemporary practitioner is familiar with the latter practice of relating to three equal lengths (even though their medieval extent is not equal to the contemporary one), we may surmise that this method was the more recent one. Accordingly, the earlier method appears to be a chi cun method, with a guan division line between the cun-inch and the chi-foot locations, which each had a different length.

The question that then arises is why and how this change came about. The second section of part one provides a clue. It discusses a method of pressing with different fingers on to mai in order to feel the frequency of pulse beats. This medieval Dunhuang text differentiates between three different fingers, namely the head, middle and third finger. Although we cannot be entirely certain about any referential meanings of medieval terms, it seems likely that 
this text refers to the same three fingers that are used today in the cun guan chi method, namely the index, middle and ring finger. Of particular interest is that according to this text the fingers were used in order to feel pulse beats. This is the more noteworthy as psychophysical research has demonstrated that the fingertips are richly endowed with Merkel cell complexes, which are sensitive to changes in pressure ${ }^{9}$ (such as those induced, for instance, by pulsation).

The third section combines the ideas put forward in sections one and two: if pulse beats were to be identified and if fingertips were well-equipped for perceiving pulse beats, physicians may have started to apply fingers to the locations cun guan chi in order to feel pulse beats. Since the width of the index, middle and ring fingers are fairly similar, one would expect the locations to which these three fingers were applied to be of identical width. Accordingly, the cun guan chi method, which involves investigating mai on the wrist at three locations of identical width, would intricately be related to the body technique of applying fingers to the wrist and using fingertips for feeling pulse beats.

Many Chinese and Western scholars believe that the ancient Chinese physicians were already interested in counting pulse beats, some because they translate the term dong mai 動脈, with reference to its modern meaning, as "pulsating artery". However, dong 動 "to beat, to be agitated, to move" is a multi-vocalic term with a wide array of connotations, and accordingly it is not certain that this term always referred to pulse beats in ancient texts. As demonstrated elsewhere ${ }^{10}$, early explorations of mai were not primarily geared towards counting pulse beats. The early medical manuscripts of the second century BC can be read to indicate that initially physicians "inspected mai" (xiang mai 相脈) or "stroked" (xun 循) them. Eventually, they also palpated mai (qie mai 切脈), as does Chunyu Yi 淳于意 in the 105th chapter of the Shi ji 史記 (Historical Records) of $c a 86 \mathrm{BC}^{11}$. Some texts in the received medical literature detail how mai were tactually explored at two locations relevant to this discussion: they $x u n$-stroked the skin of $c h i$-foot ${ }^{12}$

9 E.g. Greenspan/Bolanowski 1996, fig. 2.

$10 \mathrm{Hsu}$ in print.

$11 \mathrm{Hsu}$ in press.

12 E.g. Shi ji 105, p. 46, case 19, reports on Chunyu Yi stroking the patient's foot-area (xun qi chi 循其尺). Ling shu 4,p. 276, qualifies the skin of the chi-area (chi zhi pi fu 尺之皮膚) with the same verbs that qualify mai. See also Kato Bankei's comment on Nan jing 2, which refers to the skin of the chi-area, in Unschuld 1986, 83: "When the terms 'foot' and 'inch' were used there [in the Nei jing], 'foot' referred to the skin of the foot-[section], while 'inch' referred to the vessel in the one section of the inch-opening." 
and they qie-palpated the cun-inch, also known as the "inch-opening" (cun kou 寸口) or “mai-opening” (mai kou 脈口) ${ }^{13}$.

After establishing that Chinese physicians were not primarily interested in the heartbeat in antiquity, the second part of this article asks how the body technique of exploring mai with one's fingertips became fashionable in Chinese medicine. Naturally, it is possible that over time the Chinese physicians themselves refined their pulse diagnostic method and started to use the fingertips of the three said fingers rather than, say, the palm of the hand, for stroking along the chi-foot or palpating the mai at the cun-inch. However, as Shigehisa Kuriyama has long noted, Greek sphygmology had always been closely associated with detecting the movements of the arteries coming from the heart ${ }^{14}$. The interest in pulse beats, i.e. in the heartbeat, was a preoccupation in particular of Galenic physicians. Accordingly, Galenic physicians may have influenced the Chinese ones in medieval times (rather than Ayurvedic ones since pulse diagnostics is generally thought to have been incorporated into Ayurveda only after the Islamic conquest in the 13th century which brought with it Islamic/Galenic/Yunani medicine to the South Asian peninsula). This is a possibility that cannot be discarded entirely. However, there are other hints to suggest that the body technique of pressing with the fingers on to the mai at the wrist came from Tibetan medicine.

The first section of part two will point out that some Tibetan physicians referred to cun guan chi not as locations on the wrist but as fingers, namely the tshon-finger, kan-finger and chag-finger. Other Tibetan physicians and more recent contemporary scholarship have shown that this was a "mistake" 15 . Although it is difficult to know why Tibetan physicians committed the mistake, one need not shy away from asking the question. Did it occur due to a misunderstanding? If the entire technique was new to them, why might they have made the mistake in respect of the fingers? Perhaps, however, the technique was not new in its entirety and the misunderstanding arose because the Tibetan physicians themselves had already practised a form of pulse diagnostics and had already been familiar with using their fingers for those purposes. Perhaps, therefore, they failed to appreciate subtle differen-

13 E.g. Shi ji 105, p. 29 and p. 35, where Chunyu Yi mentioned the right "opening" of the mai (mai kou or kou) in cases 3 and 7. Wang Bing 王冰 (Su wen 11, 1982,30a) of the 8th century AD comments: "Qi kou then is cun kou, it is also called mai kou" (qi kou ze cun kou, ye, yi wei mai kou ye 氣口則寸口也, 亦謂脈口也). It is impossible to be certain about its referential meaning in antiquity and medieval times, but today it is assumed to have been on the inner side of the wrist of the hand.

14 Kuriyama 1999.

15 Meyer 1990; Zhen/Cai 2007. 
ces in meaning of the three nouns used to describe wrist locations within this novel technique. With the evidence at hand it is difficult to know.

The second section of part two discusses the term $j u$ 舉 "to offer with both hands, to lift". This term is mentioned in the medieval Dunhuang literature on pulse diagnostics but not in the early manuscript texts of the second century BC. In particular, S5614 is noteworthy as it juxtaposes phrases mentioning the body technique ju zhi 舉之 to phrases mentioning the body technique an zhi 按之. In later medical texts, such as the Mai jue kan wu 脈決刊誤 (Errors in Prints of the Mai jue), an and ju are clearly defined as meaning "to press heavily" and "to press lightly". However, this definition cannot be applied to all texts in which the two terms an and ju occur. In particular, the Dunhuang manuscript S5614 speaks of an-pressing with a light hand (qing shou 輕手), which directly contradicts the above definition of the Mai jue kan wu.

The graph an 案, interpreted as 按, is known from the early Han medical manuscript literature and although referential meanings of ancient and medieval terminology are difficult if not impossible to know, one assumes that an meant to press on to mai. Contemporary scholars generally agree that the body technique an zhi 按之 describes a situation where the patient's arm is stretched out, the palm turned upwards, the wrist supported by a cushion on the table, and where the doctor presses on to it (see fig. 1). The term ju zhi 舉之, however, remains ill understood. In some editions of some texts ${ }^{16}$, it is rendered as $j u z h i$ 舉脂 and translated as "to lift the fingers" 17 , but this is probably a scribal error (for details, see Part 1.2 "A change in body technique: feeling mai with fingers and with fingertips").

Considering that $j u z h i$ was ill understood by Chinese physicians, and that ancient texts on pulse diagnostics do not mention it, it is conceivable that the body technique and the terminology used for describing it may have been introduced into Chinese pulse diagnostics from another culture. In this context, it is noteworthy that Meyer ponders over the fact that, strangely, Tibetan literary medical sources speak of pulse diagnostics as if it were a tradition of their own ${ }^{18}$. It is as though he was hinting at Tibetans having practised some sort of pulse diagnostics before adopting the Chinese cun guan chi method. Indeed, Tibetans continue to have a very distinctive body technique for taking the pulse (one among several others). This is to hold up both of the patient's forearms while taking the pulse (see fig. 2). Notably,

16 E.g. Nan jing 5.

17 E.g. Unschuld 1986, 113.

18 Meyer 1990. 


\section{Figure available \\ in printed version only.}

Fig. 1. Pulse diagnosis in a Chinese medical context.

Source: (C) Wellcome Library, London, reprinted with permission.

neither Chinese depictions nor texts have been found to describe such a body technique. Considering that Chinese medical texts often are compilations of texts from different medical lineages that record "undecided controversies", S5614 may have recorded side by side two body techniques of different cultural provenance. The idioms an $z h i$ and $j u z h i$ would then mean "to press on to [the wrist]" and "hold up [the wrist]", the former being a Chinese, the latter a Tibetan body technique.

The last section of this article discusses medical rationale and highlights that the concept of dividing the body into upper, middle and lower burners (jiao 焦), correlating with the locations cun guan chi on the wrist, reflects a tripartite verticality characteristic of Tibetan material cultures. The possible Tibetan provenance is reinforced by textual research that cannot trace the term for the body part called "three burners" or "triple burner" (san jiao 三焦) to the early medical manuscript literature ${ }^{19}$.

19 San jiao is mentioned in the received canonical medical literature and in Shi ji 105, pp. 13-14. Much like the former, the latter may well be a compilation with interpolations dating to medieval times and later (Hsu in press). 


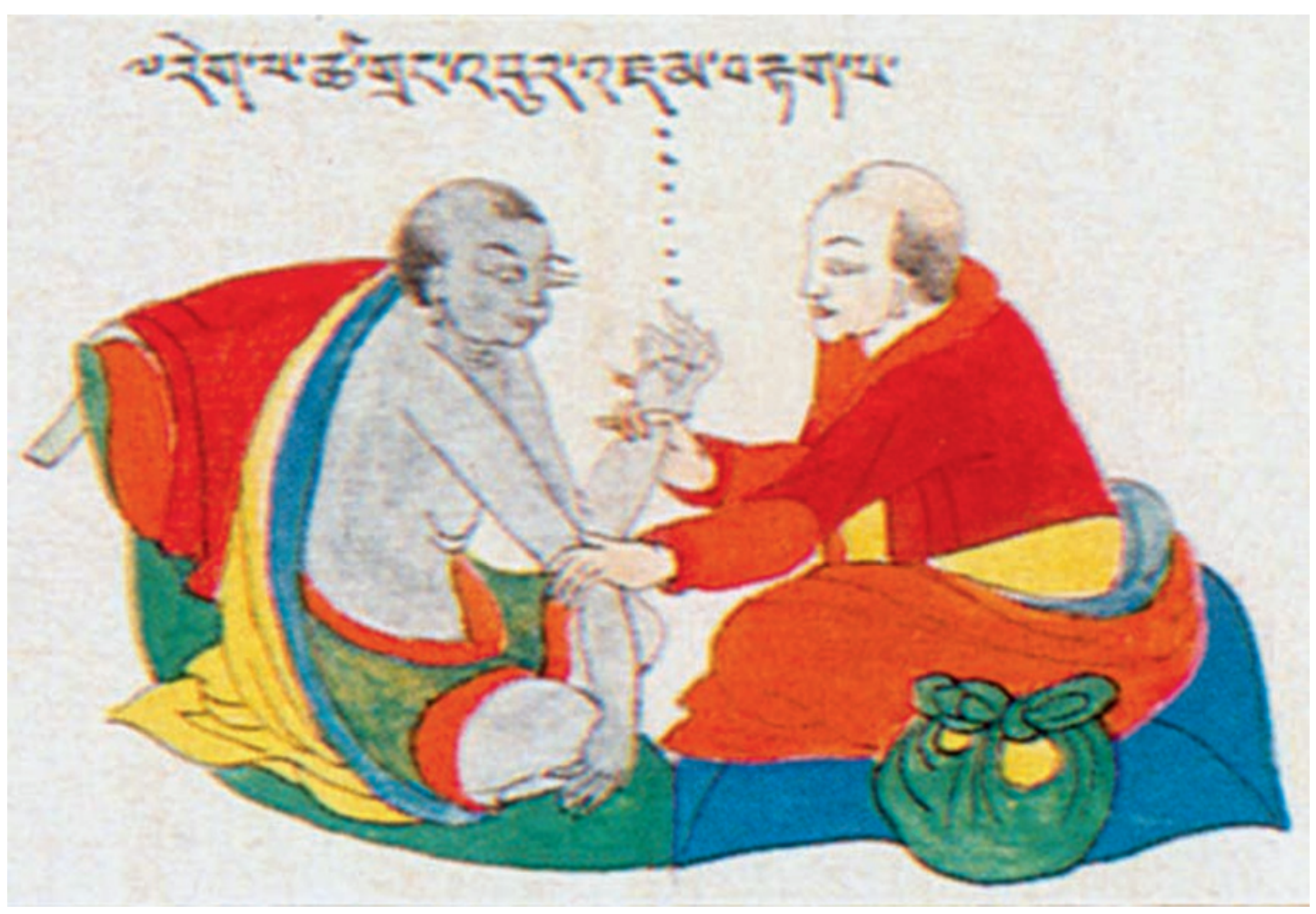

Fig. 2. Pulse diagnosis in a Tibetan medical context.

Source: Detail of plate 35 from Tibetan Medical Paintings, Volume 1 (London 1992), p. 86. Serindia Publications, reprinted with permission (C) 2008.

To summarise: considerations of both sensory experience and sensory physiology suggest that once Chinese physicians became interested in sensing pulse beats, they examined mai with their fingertips. Since the early medical manuscripts mention neither fingers and only arguably pulse beats in the context of examining mai, the question arises when and how the body technique of making use of the fingertips with their particular sensitivities became relevant to Chinese pulse diagnostics. It is possible that the Chinese themselves invented it and that the Tibetans adopted and retained it. However, it is also possible that Chinese physicians adopted this body technique from the Tibetans. In medieval times, the Dunhuang area was a cultural melting pot, and the Tibetan presence was, if not dominant, strongly felt.

\subsection{A new pulse diagnostic procedure: the cun guan chi method}

A method often discussed in the Dunhuang manuscripts is that of investigating the “three sectors" (san bu 三部): the “inch" (cun 寸), “gate” (guan 關), 
and "foot" (chi 尺 $)^{20}$. In the opening paragraph in the Dunhuang manuscript text entitled “Ping mai lüe li" 平脈略例, P2115, section 2, subsection ${ }^{21}$, these three sectors are correlated with the three burners (san jiao 三焦), which are said to reach from the head to the hand (cong tou jing shou 從頭經手), to the waist (ji yao 及腰) and from the small abdomen to the feet (cong xiao fu zhi zu 從小腹至足).

In P2115, section 5 (corresponding almost verbatim with S5614, section 5), the three sectors cun, guan, chi correlate again with the upper, middle and lower burner (shang jiao 上焦, zhong jiao 中焦, xia jiao 下焦). In this section the heart, corresponding with the small intestine on the left hand side, and the lungs, corresponding with the large intestine on the right hand side, are said to unite in the upper burner; the liver, corresponding with the gallbladder on the left hand side and the spleen, corresponding with the stomach on the right hand side, are said to unite in the middle burner; and the kidneys on the left and right hand side, corresponding with the bladder, and the "portal of the womb" (bao men 胞門) on the left or the "door to the child" ( $z i h u$ 子戶) on the right hand side are said to unite in the lower burner (cols 135 and 137). This method, admittedly in modified form ${ }^{22}$, has survived to the present day. In this article, it is referred to as the cun guan chi method.

\subsection{A change in body technique: feeling mai with fingers and with fingertips}

If one compares the texts on diagnosis in the Dunhuang manuscripts with those in the received literature, one notes that the fingers are barely mentioned in the context of discussing the pulse diagnostic methods of "examining mai" (zhen mai 診脈) and "palpating mai" (qie mai). This is not to say that fingers do not occur in the received literature, they do. However, in general, fingers are more frequently mentioned in the Dunhuang manu-

20 The medieval san bu method is distinct from the san bu jiu hou 三部九候 method described in Su wen 20, pp. 64-66 (see Deng 1984, 63), as is its modern derivate, which is sometimes referred to by this name. The medieval san bu method makes no reference to different strengths of pressing on to mai, but its modern derivate does so, in accordance with Nan jing 18, p. 243 (quoted on p. 21f.), which defines the san bu as cun, guan, chi, and the jiu hou as the three pressure levels floating, medial and sinking.

21 P2115, section 2, can be subdivided into three subsections: the first one outlines the san bu method, the second is concerned with the method of differentiating between five different pressure layers, each indicative of one of the five viscera, and the third is concerned again with the san bu method, in particular with the extension of the locations at which mai is explored (quoted on p. 19).

22 See Deng 1984, 62-64. 
script texts where the parallel text in the received literature does not mention them. Thus, S8289, section 5, col. 32, reads "it is floating underneath the finger" (fu yu zhi xia 浮於指下) where the parallel text in Mai jing 1.1, p. 1, says: "It is floating beneath the hand" (fu yu shou xia 浮於手下). P3287, section 3, col. 9, reads "with the finger subtly press onto it" (zhi wei an zhi 指微按之) where Su wen 20, p. 65, has “press on to it” (an zhi 按之) and later mentions zhong shou 中手 (palm of the hand?) ${ }^{23}$. P2115, section 2, col.115, mentions "if you hold up the finger, it comes rapidly" (ju zhi ji zhe 舉指來疾者) where Mai jing 1.6, p. 10, reads “if you hold it up, it comes rapidly" (ju zhi ji zhe 舉之來疾者 $)^{24}$.

In the literature on pulse diagnostics, the term $j u$ zhi 舉之 meaning "to hold it up" is more frequently encountered than $j u z h i$ 舉指 "to hold the finger up". This suggests that the latter is an unusual if not a mistaken rendering of the phrase ${ }^{25}$. Mistakes are always informative. This one suggests that fingers figured prominently in the minds of the scribes who copied the medical texts now contained in the Dunhuang corpus.

Another Dunhuang text, P3655, verse 4, differentiates in the context of the cun guan chi method three different kinds of "fingers" ( $z h i$ 指):

\footnotetext{
"The left hand's middle finger is the indicator of the liver" (zuo shou zhong zhi gan zhi hou 左手中指肝之候) ...." “the right hand's middle finger links the eyes with each other" (you shou zhong zhi mu xiang lian/yun 右手中指目相連) ...., “the left hand's kidney mai is called the third minister" (zuo shou shen mai ming san xiang 左手腎脈名三相) .... "the right hand's lung mai looks at the first finger" (you shou fei mai kan tou zhi 右手肺脈看頭指) ...., "the right hand's spleen mai links with the middle finger" (you shou pi mai lian zhong zhi 右手脾脈連中指) ..., “the right hand's mai of fate is beneath the third finger" (you shou ming mai san zhi xia 右手命脈三指下) ...
}

The text is not entirely systematic, but it does mention three fingers systematically on the right hand side: the "head finger" (tou zhi 頭指), "middle finger" (zhong $z h i$ 中指) and "third finger" (san zhi 三指). The text also repeatedly speaks of pulse qualities felt "underneath the finger" (zhi xia 指下 $)^{26}$.

23 zhong shou 中手 lit. "interior hand", meaning uncertain; perhaps, "palm of the hand"?

24 In this case, Nan jing 5 (Unschuld 1986,113) has the same reading as the Dunhuang text; the Qian jin yao fang 28.2 千金要方 reads like Mai jing 1.6, but the Qian jin yi fang 25.2 千金翼方 follows Nan jing 5.

25 The suggestion that $j u z h i$ 舉指 is a scribal error, first presented at the conference "Chinese medicine: a visual history" in Beijing, 14-16 Sept 2005, was reconfirmed by several Chinese historians of medicine, among them Liao Yuqun (p. c.).

26 The medieval referential meaning of these fingers cannot be deduced from the Dunhuang manuscript, but according to the contemporary cun guan chi method, here taken as a hint, the index presses on to the cun-location, the middle finger on to the guan-location and the ring finger on to the chi-location, correlating with heart and lungs, liver and spleen, and kidneys and the gate of life respectively (Deng 1984, 63). 
Why use fingers? P3655, verse 4, speaks not only of fingers, but also of "agitations" (dong 動). They are given in comparatively high numbers, ranging from forty-five to seven:

“If after every forty-five beats, there is one pause” (si shi wu dong wei yi xi 四十五動為一息) ..., "if after forty-five beats, without anything else being the matter, and if after thirty-one beats, it is suddenly sunken" (si shi wu dong wu ta shi, san shi yi dong hu ran chen 四十五動無他事 三十一動忽然沉) ..., “if after seven beats, it is sunken, sunken to the degree that it does not return” (qi dong chen chen geng bu huan 七動沉沉更不還) ...

The forty-five beats (dong), followed by a pause, indicate "wind poison" (feng $d u$ 風毒) and "heat at its extreme" ( $r e j i$ 熱極), the seven beats immanent death; a variety of other pulse conditions in between indicates various other disorders. A rapid pulse beat may well indicate fevers and an arrhythmic one death, but one hesitates to unreflectively attribute this referential meaning to dong in this medieval text. As repeatedly emphasised ${ }^{27}$, a common fallacy of explaining word meaning is to pick a word out of context and attribute it meanings of contemporary common sense, which in the case of dong mai would be to translate it as "pulsating artery". As detailed elsewhere ${ }^{28}$, dong has too many connotations in self-cultivation and medicine that any attempt is bound to be flawed that explains it merely in the light of its referential meaning in contemporary contexts. Particularly in the early medical manuscript literature dong appears to have connotations that contemporary scholarship tends to overlook ${ }^{29}$. Despite all these caveats, one cannot evade the impression that in this particular Dunhuang manuscript text, and perhaps also in some others, dong does appear to refer to pulsations and the heartbeat.

P3655, verse 4, suggests that medieval Chinese physicians started to become interested in identifying pulsations. It may not be coincidence that explicit reference to the bodily technique of employing fingers in the exploration of mai arose in the context of counting pulsations, and by implication the heart beat as felt in the arteries at the wrist. From a psychophysical point of view, it is worth noting that differentials in pressure, which are generated by pulsations, can particularly well be sensed with the fingertips because their sensory endings are richly supplied with Merkel-cell complexes. Figure 3 highlights their distribution in the glabrous skin of the palm: the high innervation density of the fingertips is striking ${ }^{30}$. If one assumes that this contemporary psychophysical finding applies also to human bodies in medieval times, it appears reasonable to suggest that physicians should have

27 Hsu in press.

28 E.g. Hsu in print.

29 E.g. Pfister forthcoming, vol. 2, ch. 5.1.

30 Greenspan/Bolanowski 1996, 34, see their figure 2. 


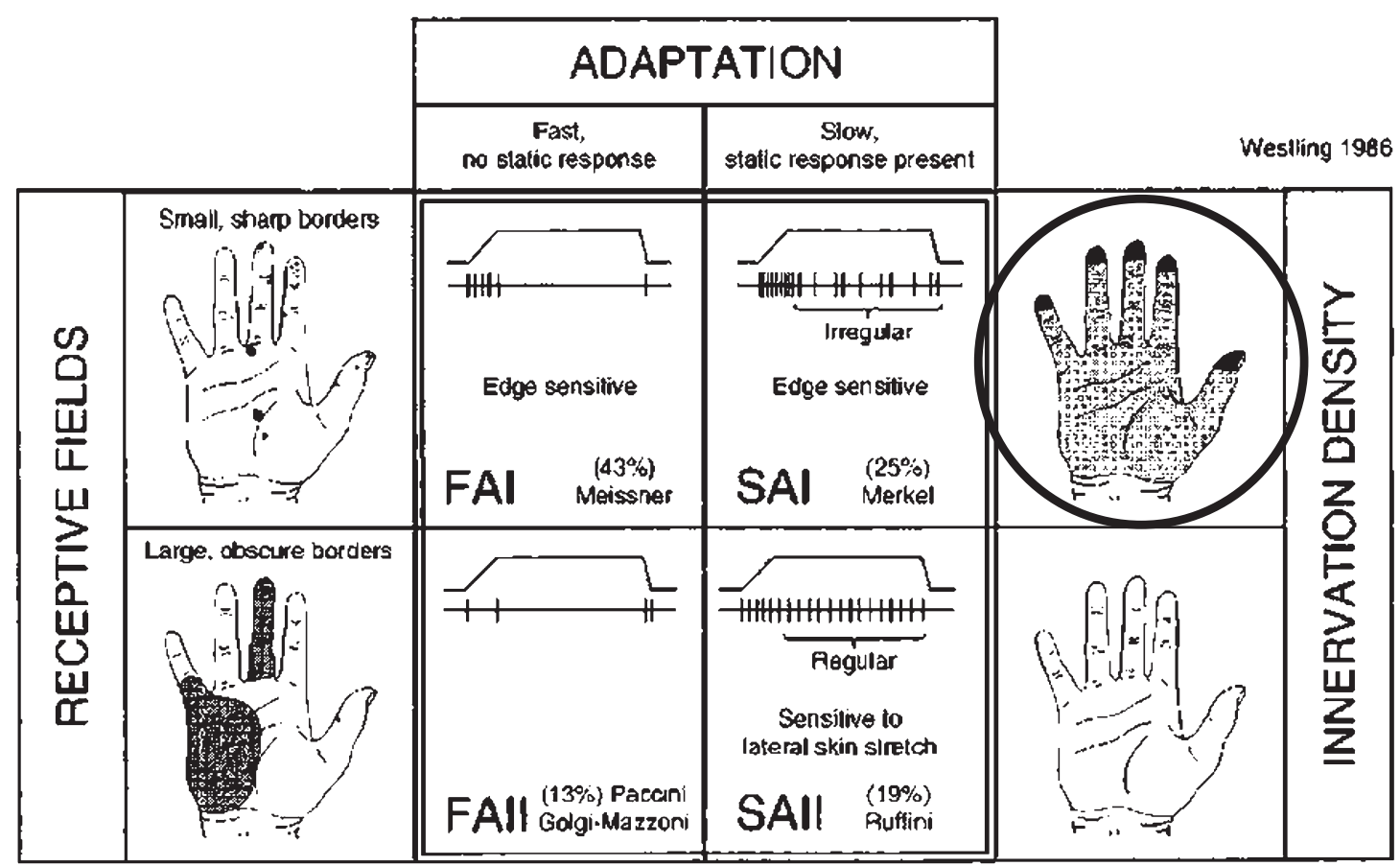

Fig. 3. Characteristics of the four types of mechano-receptive afferents that innervate the glabrous skin of the human hand. (Figure within ring indicates the density of the Merkel-cell complexes; dark means high density, light means low density.)

Sources: Greenspan J. D./S. J. Bolanowski, "The psychophysics of tactile perception and its peripheral physiological basis," in: L. Kruger (ed.), Pain and Touch (San Diego 1996), 25-103; fig. 2, p. 34; reproduced from Göran Westling, Sensory-Motor Mechanisms during Precision Grip in Man (1986), ISSN 0346-6612 Umeå University Medical Dissertations, New Series No 171, fig. 1, p. 5 (with permission of the author).

started to explore mai with their fingertips once they felt it necessary to count pulsations.

\subsection{Three equal extents of the three locations cun guan chi}

The cun guan chi method is described neither in the Su wen nor in the Ling shu, while both mention the $c h i$-foot and the $c u n$-inch, and sometimes use the compound word chicun, which pointed to the pulse diagnostic method of investigating both the cun and the chi area ${ }^{31}$. It is not quite clear what kind of tactile experiences the physicians sought who investigated these areas. The texts in question often contain verbs describing pulse qualities, but the referential meaning of those is notoriously difficult to establish. In this context, a

31 On chi cun, see Su wen 5, p. 23; 67, p. 187; 78, p. 249 and Ling shu 3, p. 273, 9, p. 293 and 38, p. 372; chi and cun are also mentioned in Su wen 74, p. 232 (based on computer searches by Wang Zilan 2005, p. c.). 


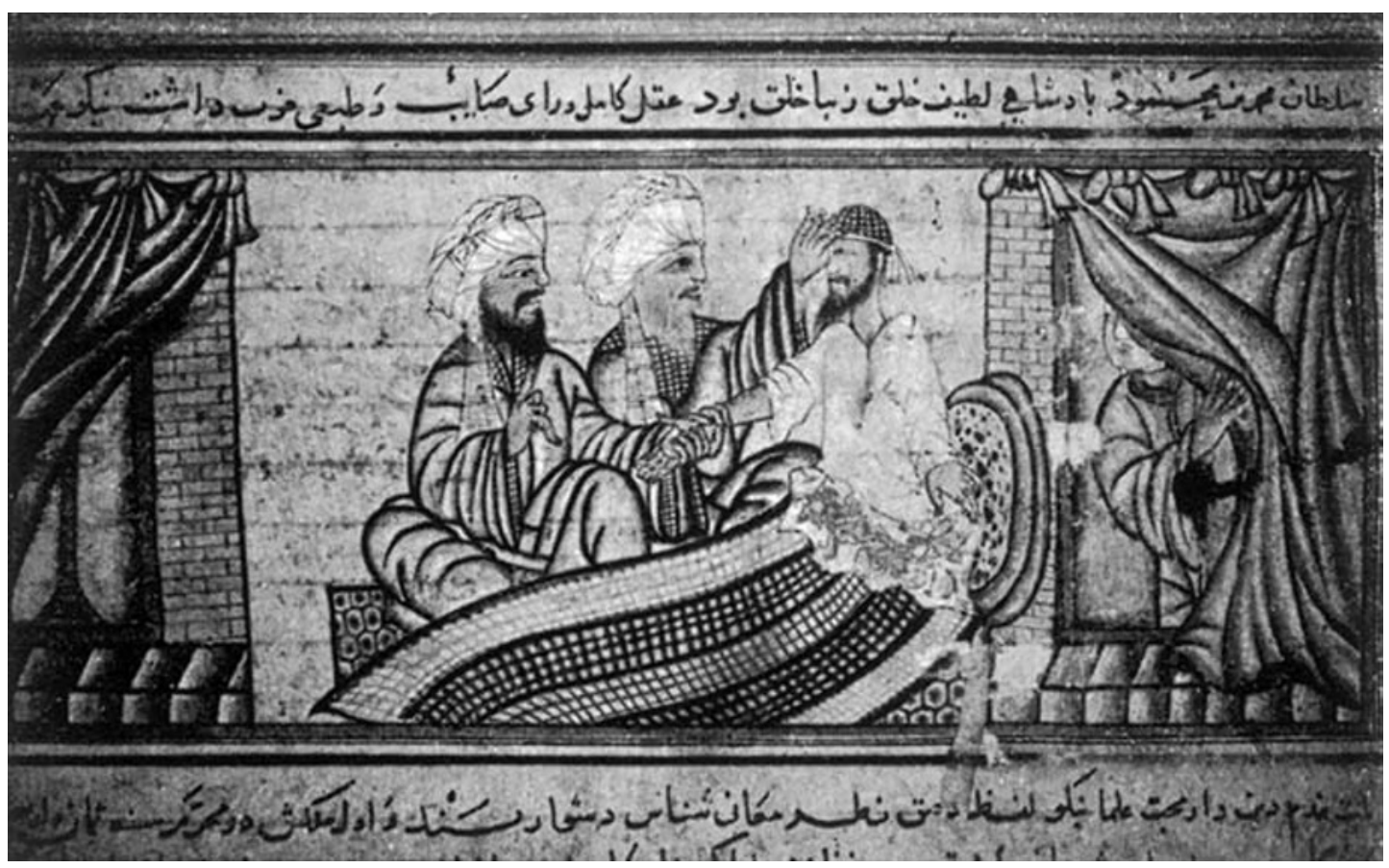

Fig. 4. Two physicians attending to the patient Mesud b. Muhammed b. Melikash (1135-1152), a Seljuq sultan: one takes the pulse at the wrist and the other the temperature on the front.

Source: Rasid ad-Din, Gami at-Tawarth. Manuscript of the Topkapi Palace, Hazine library, no 1653, p. 321; date of the miniature and manuscript: 1314. Reproduced in: Terzioglu, A., "Die Bedeutung der chinesischen Pulslehre für die Krankheitsdiagnostik nach der persischen Handschrift Tank-suqname-i Il-Han dar Fununi-i Ulumi-i Hita'i aus dem Jahre 1313 n. Chr.", in: C. Habrich, et al. (eds), Medizinische Diagnostik in Geschichte und Gegenwart (München 1978) 71-80; p. 79.

passage in $S u$ wen 28, p. 86, is of particular interest as it notes that the chi and the cun areas can become either hot or cold.

In cases where the jing-channels are depleted and the luo-links are full, the chi-area is hot and full and the mai opening is cold and rough, in [all] those cases spring and summer die, autumn and winter thrive.

經虛絡滿者 尺熱滿脈口寒濇也 此春夏死秋冬生也

Without attempting to explain the above passage in its entirety, we note that physicians were interested in either the hot and full or the cold and rough, at either the cun- or chi-area (assuming that the cun-area coincides with that of the mai opening, which is very likely, see footnote 13). While Chinese medical texts provide barely any hints about the body technique used for feeling heat and coldness, fullness and roughness, research into their semantics takes them as static verbs of touch ${ }^{32}$. Although no anatomical diagram

32 Hsu in press. 
has been found that details how the nerve endings sensitive to heat and coldness are distributed in the hand, daily life experiences may provide a hint: in contemporary Europe, as in medieval Persian contexts (see fig. 4), one tends to use the palms for feeling temperature, for instance, for determining whether a patient has a fever. Perhaps, physicians stroked (xun) the chi-area and palpated (qie) the cun-area with their palms? It is difficult to know.

In this context, Mai jing 1.3, p. 5, is worth noting. Apart from speaking of yin and yang, notions that often imply the hot and cold, Mai jing 1.3 discusses the size of the locations cun-inch and chi-foot on the forearm.

From the Fish Line to the Prominent Bone, one travels just one inch, the area in the midst of it is called inch-opening. If from the inch one reaches out a foot, [the area one gets to] is called the Marsh of the Foot-area ${ }^{33}$. Hence one calls it the inch and foot [chi cun method]. Behind the inch and before the foot, it is called the gate. Yang exits, yin enters, one takes the gate as a boundary.

從魚際至高骨, 卻行一寸, 其中名日寸. 口從寸至尺, 名日尺澤, 故日尺寸. 寸後尺前, 名日關. 陽出陰入 以關為界.

Mai jing 1.3 explains that the length of the cun-inch was one inch and that of the chi-foot one foot long, and the guan-gate a boundary line between them ${ }^{34}$. Important here is that Mai jing 1.3 discusses the three terms cun-inch, chifoot and guan-gate, in this sequence, rather than referring to cun guan chi which figures so prominently in the Dunhuang manuscripts.

The Dunhuang manuscript P2115, section 1, subsection 3 (and with variations, the parallel text P3477, part 1, section 2), also discusses the size and extent of these three locations (in the context of the discussion presented in Part 1.1 "A new pulse diagnostic procedure: the cun guan chi method"). It juxtaposes two mutually contradictory statements:

The three sectors always are distanced from each other by one inch, together they make up three inches.

三部輙相去一寸, 共成三寸也。

The location of the "inch-opening" (cun kou) is eight fen, the location "above the gate" (guan shang) is three fen, and the location of the "interior foot" (zhong chi; viewed on 18.6.02) is eight fen, in total it amounts to one inch nine fen.

寸口位八分, 關上位三分, 中尺位八分, 為共成一寸九分也。

These two sentences, which evidently contradict each other, have to be seen as the result of the work of a compiler, who was interested in giving a precise measurement for the extent of the locations of pulse diagnostic investigation and compiled side by side whatever information he found on this theme. The

33 Practitioners today identify the Fish Margin (yuji) as thenar eminence, the Prominent Bone (gaogu) as radial styloid process and the Marsh of the Foot (chize) as an acupuncture point on the elbow (e.g. Yang 1997, 7). Accordingly, the entire forearm, from the Fish Line to the Marsh of the Foot-area, i.e. from wrist to elbow, was investigated for diagnostic purposes. 34 See also diagram by Unschuld $(1986,88)$. 
viewpoint that each was three inches wide, with each location one inch wide, is innovative in comparison to Mai jing 1.3 in that it postulates that all three locations have an equal length. The extent of the three locations together totalling one inch and nine fen 分 invokes the numerology of yin and yang, as represented by the odd number nine and even number ten, which add up to nineteen, a number that was considered representative of the universe in its entirety according to some Dunhuang manuscript texts on pulse diagnostics ${ }^{35}$. In contrast to Mai jing 1.3, the medieval Dunhuang manuscript text P2115 gives the location guan an extent: it is either one inch or three fen wide. If fingers were used at these locations for sensing pulsations, it is possible, if not likely, that the more or less equal width of the fingers was taken as unit of measurement ${ }^{36}$.

In summary, the first part of this article has demonstrated that in medieval Chinese medicine a new technique of using three fingers for palpating mai became prevalent. This technique was marked by an interest in the pulse beat. The question that now arises is who had the idea of using these three fingers for palpating mai? Without contesting the suggestion that the basic rationale of Chinese pulse diagnostics was imported into Tibetan medicine, there are hints that at the level of body techniques, Tibetan practices transformed the Chinese ones. They are discussed in what follows.

\subsection{A Tibetan "misunderstanding" of cultural translation: are tshon, kan, chag three fingers or three locations for taking the pulse?}

The corresponding terms for cun, guan, chi are tshon, kan, chag in Tibetan medicine. However, both Meyer and Zhen/Cai point out that these three locations for taking the pulse were wrongly glossed to mean index, middle and ring finger ${ }^{37}$. The fact that locations on the wrist were translated as fingers in Tibetan treatises would suggest that these three fingers were central to the procedure of investigating mai in the context of applying the cun guan chi method. As already noted, there is no indication that fingers were used for investigating mai since time immemorial in Chinese medicine, and the scribal preferences and/or "mistakes" observed in the Dunhuang manuscript texts (see Part 1.2 "A change in body technique: feeling mai with fingers and

35 See Hsu forthcoming.

36 Incidentally, in the context of acumoxa therapy today, three fingers make up one cun,i.e. ten fen (fieldwork 1988/89). Accordingly, the width of a finger is just about three fen. To be sure, this cannot be used as evidence for the above argument. However, it is an interesting coincidence.

37 Meyer 1990; Zhen/Cai 2007. 
with fingertips"), suggest that the use of fingers for the diagnostic purpose of examining mai became fashionable only in medieval Chinese medicine.

Contemporary historians of Tibetan medicine agree that the Tibetan names of the three fingers tshon, kan, chag are transliterations from the Chinese. They cannot explain, however, why this "misunderstanding" happened. In this context, it is worth noting that contemporary Tibetan physicians have a very distinctive body technique of taking the pulse: with both hands they hold up both wrists of the patient. This body technique clearly requires a physician to clutch the wrist of the patient with his or her fingers. It is depicted, among other pulse diagnostic techniques, in a Tibetan thanka of the 17 th century (fig. 2 ).

\subsection{A Chinese “misunderstanding” of cultural translation: did ju zhi 舉之 designate a body technique of "offering with both hands"?}

As emphasised earlier, only a few texts detail pulse diagnostic body techniques. Among the few body techniques discussed is that which involves pressing with different strengths on to the flesh, skin or mai. In early medical manuscript texts, such as the Zhangjiashan "Maishu"38, and also in the medieval ones, such as S5614, part 1, section 8, col. 148 [viewed on 28.8.03], the usual term is an 案, which is used as a substitute for an 按 “to press". In texts of the received medical literature and in the medieval medical manuscripts the term ju 舉 "to hold up, to lift" is also mentioned.

In the Dunhuang medical manuscript S5614, part 1, section 8, col. 140, the pulse quality jin 緊 (tight) is identified once by palpating mai with a "light hand" (qing shou 輕手), once with a "heavy hand" (zhong shou 重手) $)^{39}$. The difference that the text S5614, part 1, section 8, invokes between investigating mai in a light- and heavy-handed fashion is reminiscent of that in P2115, section 7 (and the corresponding S5614, part 1, section 7), which appears to differentiate between a body technique of $f u$ 浮-floating and chen 沉-sinking into the $m a i^{40}$.

38 ZJS 2001, 245.

39 Perhaps, this distinction between light- and heavy-handed pressing may have elicited a pair of pulse qualities called “deep" (shen 深) and “subtle” (wei 微) in the Dunhuang manuscript text P3481?

$40 \mathrm{It}$ is also reminiscent of that in the "Mai fa" of case 5 in Shi ji 105, p. 32. However, in other texts and in contemporary pulse diagnostics, these verbs are used to qualify the tactile perception of the patient's mai rather than the physician's body technique of applying different pressure levels to mai. "Floating" ( $f u$ ) and "sunken" (chen) belong among the twenty-four standard pulses discussed in Mai jing 1, p. 1. 
A corresponding pair of body techniques is also given in a much later work of the Yuan dynasty (1271-1368 AD), the Mai jue kan wu 脈訣刊誤, appendix, p. 5a: "If you take it [the mai] with a light hand, you call it $j u$, if you take it with a heavy hand, you call it an" (qing shou qu/ju zhi yue ju, zhong shou qu/ju zhi yue an 輕手取之日舉, 重手取之日按). Accordingly, contemporary physicians consider an zhi 按之 (to press on to it) and $j u z h i$ 舉之 (to hold it up) to refer to different pressure levels that the physician applies to mai for diagnostic purposes ${ }^{41}$. However, as the contemporary author Zhao himself notes, this interpretation does not always make sense. Thus, in the same paragraph of the Mai jue kan wu we find statements that stand in direct contradiction to the above definition of $j u$ meaning "to take it with a light hand" and an "to take it with a heavy hand".

For instance, the sentence of the Mai jue kan wu, appendix, p. 5a, following the above one differentiates between "floatingly pressing" ( $f u$ an 浮按), "pressing by sinking down deeply" (chen an 沉按) and "pressing at an intermediate level" (zhong an 中按). This directly contradicts the previous sentence, as it speaks of an-pressing with three different strengths on to mai! This idea of applying three different pressure levels to the mai is also given in Nan jing 18, p. 243: "As to the three sections, they are the inch, gate and foot; as to the nine indicators, they are floating, intermediate and sunken" (san bu zhe cun guan chi ye; jiu hou zhe, fu zhong chen 三部者寸關尺也, 九候者浮中沉也). Both passages outline a method that is still advocated today, which consists of applying three different degrees of pressure on to the $m a i^{42}$. There is no evidence in the extant Dunhuang material that three different pressure levels were applied to mai, as is customary today, and as is given in Nan jing 18 and in the Mai jue kan wu, appendix, p. 5a. However, there are Dunhuang texts that contain evidence of pressing with different strengths on to mai. Thus, S5614, part 1, section 8, refers to two different pressure levels, namely an-pressing with a light or heavy hand, and S5614, part 1, section 2 , (and parallel text passages) ${ }^{43}$, distinguishes between five different pressure levels.

The medieval Dunhuang texts thus reflect an understanding of an-pressing that directly contradicts the above definition of the Mai jue kan wu. In particular, in S5614, part 1, section 8, an-pressing can be done with a heavy or a light hand. S5614, section 8, cols 134 and 136 concern the pulse qualities

41 E.g. Zhao 1992, 180-182.

42 Deng 1984, 64.

43 The parallel passages are: the Dunhuang manuscripts texts P2115, section 2; P3477, part 2, section 2; P4093; and Nan jing 5 (Unschuld 1986, 113-117), Mai jing 1.6, pp. 9-10. Qian jin yao fang 28.2, p. 493, Qian jin yi fang 25.2. p. 300. 
“sunken" (chen 沉) and "hidden” ( $f u$ 伏) respectively: "If one presses heavily, one gets it" (zhong an nai de 重按乃得) and “If one presses on to it extremely heavily until one reaches the bone, then one gets it" (ji zhong an zhi zhi gu nai de 極重按之至骨乃得). However, S5614, part 1, section 8, col. 148, which concerns the pulse quality “weak" (ruo 弱) reads: "If one presses on to it with a light hand, then one gets it, if one presses with a heavy hand, then one does not get it" (an zhi qing shou nai de, zhong [reading based on the original viewed on 27.8.03] shou bu de 按之輕手乃得, 重手不得). This statement in S5614 directly contradicts the above definition of an-pressing in the Mai jue kan $w u$, appendix, p. $5 \mathrm{a}^{44}$.

In summary, the term an "to press" is mentioned already in early Han medical manuscripts in the context of investigating mai for diagnostic purposes and continues to be used in the received literature. It is the case that it is sometimes used in the sense of "to press hard" in contradistinction to $j u$ "to press lightly" or "to lift up", as defined in the Mai jue kan wu, appendix, p. 5a. However, in many texts an-pressing involves pressing on to mai with different strengths, not only with a heavy hand.

By contrast, the term $j u$, which is not mentioned in the early medical manuscripts, appears in the manuscript literature for the first time in the medieval Dunhuang texts, most conspicuously in S5614, part 1, section 8, where it is used in opposition to an. For making sense of this term in medieval times, let us consider the basic meaning of $j u$, which is to raise and lift something upwards and make an offering ${ }^{45}$, rather than interpreting it in the sense it has in the Mai jue kan wu from the Yuan dynasty. Perhaps, ju zhi meant to hold up the mai, by clutching one's fingers around the wrist and lifting the patient's hand upwards (in the fashion some modern Tibetan doctors take the pulse, see fig. 2)? In that case an zhi probably meant to press down on to the mai in a fashion akin to that of late Imperial and modern Chinese doctors (with the turned wrist being supported by a cushion on the table, see fig. 1).

Considering that Dunhuang was a cultural melting pot, it is also possible that the scribe of the Dunhuang manuscript S5614, part 1, section 8, listed two body techniques of different cultural provenance in juxtaposition. Perhaps, he understood $j u$ in the sense of "holding up with both arms" both wrists of the patient, while later Chinese physicians misinterpreted $j u$ in the sense of "to press lightly" onto mai.

44 The phrase was misread by the Chinese editors of the text (Ma et al. 1998, 98), perhaps precisely because they had the Mai jue kan wu definition in mind.

45 Karlgren 1957, 38, 75a. 


\subsection{The vertical alignment of the viscera in the cun guan chi method}

From a conceptual viewpoint, there are at least two reasons for suggesting that the cun guan chi method may have been informed by Tibetan medicine. They are found, first, in the vertical alignment of a body that is divided into three layers and, second, in the centrality of anatomical considerations that prompted the ordering of internal body parts in those three layers.

The importance of the number three, which is fundamental to Ayurveda ${ }^{46}$, is also contained in Tibetan medical rationale ${ }^{47}$. In fact, it is central to Tibetan cultures in general. Furthermore, the tripartition is often disposed along a vertical axis, as for instance found in the vertical alignment of spaces in a Tibetan house, the top floor being for the gods, the first floor for human beings and the ground floor for the animals ${ }^{48}$. This is not to say that in ancient Chinese cosmology there was no notion of a threesome unity. For instance, heaven (tian 天), earth ( $d i$ 地) and man (ren 人) formed a threesome unity, but not one of heaven-man-earth along a vertical axis: the unity typically consisted of the pair heaven and earth, with man in between ${ }^{49}$. This threesome unity of heaven and earth, with man in between, provides a framework for the diagnostic procedure called "the three parts and nine indicators" (san bu jiu hou) in Su wen 20 but, interestingly, it is barely invoked in the context of the cun guan chi method ${ }^{50}$.

In fact, neither the $S u$ wen nor the Ling shu mention the cun guan chi method, while the Mai jing and Nan jing discuss it quite extensively, and the medieval Dunhuang manuscript texts, in particular, accord this method foremost importance (as is evident from the frequency with which it is discussed and the prominence it enjoys in the texts that discuss it: their opening sections). The cun guan chi method maps the internal viscera on to the three locations on the wrist in a fashion that reflects anatomical considerations. The heart and lungs, the condition of which was felt at the cun-inch, were thought to be located in the upper body parts or the "upper burner"; the spleen and liver, which correlated with the guan-gate, were located in the

46 Zimmermann 1987.

47 E.g. Meyer 1990.

48 Dollfus 1989.

49 Hsu 1999, 118.

50 Unfortunately, the published transcription of the Dunhuang manuscript P3477, col. 2 (Ma et al. 1998, 152) is currently punctuated such that it reads as though each of the three sectors corresponded with either heaven, man or earth (in this sequence). However, in fact, none of these three characters, neither that for heaven nor man nor earth, is given on the original manuscript (viewed on 18.6.02). P3744, cols 4-5 do mention heaven and earth, and arguably man (in this sequence), however, only with regard to the three indicators in each sector (i.e. the nine indicators of the three sectors, san bu jiu hou). On the textual history of $\mathrm{P} 3477$, see Hsu forthcoming. 
"middle burner"; and the kidneys, which correlated with the chi-foot, resided in the "lower burner" (see Part 1.1 "A new pulse diagnostic procedure: the cun guan chi method") $)^{51}$.

Evidently, the term san jiao (the three burners), which is not mentioned in the early Chinese medical manuscript literature, figures prominently in the discussion of the cun guan chi method. It typically divides the body into three layers along a vertical line, much as the spaces in a Tibetan house are layered. Notwithstanding, the medieval texts report on variations in the layering, as becomes evident when one compares P2115, section 2, subsection 1 with P2115, section 5 (both quoted in Part 1.1). Furthermore, in P2115, section 5, cols 131-137 (quoted in Part 1.1), san jiao is not regarded one of the six cavities (liu fu 六腑), as known from the canonical Ling shu 10 (but it is mentioned as such in the following section of the same Dunhuang manuscript, cols 137-139).

In the received medical texts of the Inner Canon, the term "burner" (jiao) is also used in a variety of different ways ${ }^{52}$. Interestingly, the $S u$ wen texts, which mention it ${ }^{53}$, are framed in a numerology of two rather than three. Thus, the "triple burner" forms a pair with the bladder (san jiao pang guang 三焦膀胱) in Su wen 8,p. 28;9,p. 32 and 11,p. 3754. The "upper burner" is mentioned in Su wen 39, p. 113, and Su wen 63,pp. 170-171. In Su wen 63, it is associated with pathologies of the hot and cold. In Su wen 39, it is mentioned together with the "lower burner" - and the textual parallels in Tai su 太素 2, p. 3, and 1, p. 12, even mention the term "two burners" (liang jiao 兩焦) ${ }^{55}$. Despite its current name san jiao, which invokes a triad, the above would suggest that the authors of the above $S u$ wen texts conceived of jiao in dualities, namely in terms of burner and bladder, the upper and lower, the hot and cold.

51 For the precise attributions in various Tibetan treatises, see Meyer 1990, 226. Interestingly, the mapping of the inner and outer aspects of the viscera on to the wrist, as advocated in the Dunhuang texts, continued to be promulgated in Tibetan but not in Chinese medicine.

52 Su wen 8, p. 28, the locus classicus for defining san jiao, associates it with water regulation. However, there are reasons for translating jiao as "burner". In Ling shu 36, p. 369, the triple burner sends out qi in order to warm the flesh and fill the skin (san jiao chu qi yi wen ji rou chong pi fu 三焦出氣 以溫肌肉 充皮膚). See also Ling shu 81, p. 480. Consider also Ling shu 30, p. 357, with zhong jiao as "interior burner" located in the centre of the body. Depictions of the body from the 10th to 11th century AD show a “jade oven" ( $y u$ lu 玉盧) above the bladder (in Pfister 2006).

53 All occurrences in the $S u$ wen are listed in what follows, based on Hanson (unpublished) and my own computer searches.

54 Furthermore, the "lower burner" and the bladder arguably form a pair in Su wen 23, p. 74.

55 This is telling, as the Tai su was not subject to the same editorial processes as the Su wen during the Song dynasty. See footnote 6. 
In the Ling shu, the three burners, two burners, upper burner, lower burner and medial burner are more frequently mentioned, although they are again mostly mentioned in pairs, namely "the upper and medial" or "the lower and medial" burner ${ }^{56}$. It is only in the Dunhuang manuscript texts that the term san jiao enjoyed centrality in the context of discussing a tripartite entity, namely the layered sequencing of the internal viscera as given by the cun guan chi method. This strongly suggests that the concept of the san jiao as "three burners" or "triple burner", framed within a numerology of three, became predominant in medieval times.

To be sure, san jiao itself has no anatomical equivalent in biomedicine. However, the concept was used for mapping the viscera in an architectural fashion into the body. The vertical alignment of the tripartite layers of the well-known five viscera, to which a sixth entity was added, reflects anatomically strikingly correct knowledge. Such insistence on accurate anatomical knowledge points again in direction of Tibetan cultures. In the context of pulse diagnostics, it is worth noting that in Tibetan treatises, the liver correlates with the kan-location on the right hand side and the spleen with the kan-location on the left; this contrasts with the Chinese understanding, but reflects accurate anatomical knowledge ${ }^{57}$. In summary, the tripartite vertical alignment of the internal viscera, which reflects an undeniable interest in and knowledge of anatomy, points in the direction of Tibetan rather than Chinese cultures.

\section{Discussion}

In this article, I have argued that the pulse diagnostic method cun guan chi, which figures prominently in the medieval Dunhuang manuscript texts, was not known to Chinese physicians since time immemorial but dates back to medieval times. There is general consensus that the cun guan chi method is an elaboration of the Chinese chi cun method, which, as underlined in this article, was framed in a numerology of two, attending to the full and rough, hot and cold, yin and yang.

Innovative features of the cun guan chi method, as put forth above, were its interest in detecting the heart beat and pulse beats, its insistence on using fingers (presumably for detecting pressure differentials caused by the pulsa-

56 Based on Hanson (unpublished) and my own computer searches. They also occur in discussions of the "nourishing qi" (ying $q i$ 營氣) and the "defensive $q i$ ” (wei $q i$ 衛氣) in e.g. S202, section 16, cols 79-96 (see also Porkert 1974,161).

57 Meyer 1990; Zhen/Cai 2007. 
tions) and its framing in the numerology of three. The tripartite vertical alignment of the viscera, which is intrinsic to the cun guan chi method, reflects: (a) accurate anatomical knowledge and (b) a sense for verticality. Anatomy probably played a more prominent role in Tibetan medicine than in Chinese medicine; verticality certainly is a striking feature of Tibetan material cultures in general.

While the findings in this article primarily contribute to the history of Chinese pulse diagnostics, it is hoped that the methods employed in it may inspire research on the history of the body and medicine more generally. The article, evidently built on text critical research ${ }^{58}$, also transposed insights from research on contemporary transnational exchanges into medieval times, for instance, that misunderstandings constructively contribute to cross-cultural communication ${ }^{59}$. It did not limit itself to investigating medieval ideas and concepts of the body but discussed those in relation to body techniques.

In particular, this article aimed to explain a historically given change of a body technique with a focus on body perception in order to explain the intentions of the practitioners involved in prompting the observed change. It highlighted that the ancient Chinese physicians, who for diagnostic purposes were interested in identifying feelings of heat and coldness, fullness and roughness, yin and yang, were likely to have explored the body surface and the mai with their palms, while those interested in counting pulsations, may have been prompted to use their fingers, in particular, their fingertips. The study also showed that the interpretation of ancient and medieval texts is not always distorted by modern scientific knowledge. Rather, it can throw light on how local idioms relate local understandings of biological processes, if judiciously employed, and thereby help strengthen a line of argumentation that explores the rationale of culture-specific practices.

\section{Bibliography}

\section{A. Modern works}

Cong, Chunyu 從春雨 (ed.), Dunhuang Zhongyiyao Quanshu 敦煌中醫藥全書 (A Complete Book of Dunhuang Medicine) (Beijing 1994)

Deng,Tietao 鄧鐵濤/et al. (eds), Zhongyi zhenduanxue 中醫診斷學 (TCM Diagnostics) (Shanghai 1984)

Despeux, C. (ed.) forthcoming, Médecine, religion et société dans la Chine médiévale: les manuscrits médicaux de Dunhuang (Paris)

Dollfus, P., Lieu de neige et de genévriers: Organisation sociale et religieuse des communautés bouddhistes du Ladakh (Paris 1989)

58 Keegan 1988.

59 Hsu in prep. 
Greenspan J. D./S. J. Bolanowski, "The Psychophysics of Tactile Perception and its Peripheral Physiological Basis", in: L. Kruger (ed.), Pain and Touch (San Diego 1996) 25-103

Hanson, M., "The Triple Burner (sanjiao) in the Inner Canon: a Chinese Medical Morass" (unpublished paper, 71 p.)

Harper, D., Early Chinese Medical Literature: The Mawangdui Medical Manuscripts (London 1998)

Hsu E., The Transmission of Chinese Medicine (Cambridge 1999)

- forthcoming, "Sphygmology, Chapter II, Introduction: Le diagnostic du pouls dans la Chine médiévale", avec des notices sur la sphygmologie dans les manuscrits de Dunhuang: P2115, P3106, P3287, P3477, P3481, P3655, P4093, S79, S181, S202, S5614, S6245, S8289”, in: C. Despeux (éd.), Médecine, religion et société dans la Chine médiévale: les manuscrits médicaux de Dunhuang (Paris)

- (in press), Pulse Diagnosis in Early Chinese Medicine: the Telling Touch (Cambridge)

- (in print), "Mai: shiguan dao tingguan tai dao chuguan zhencha: yunyong 'shentigan' dui Handai zaoqi yixue shougao de xin jieshi 脈, 視覺到聽覺再到觸覺診查: 運用「身體感」對漢 代早期醫學手稿的新解讀 (From a visual to an auditory and tactile exploration of the mai-vessels: a new interpretation of the early Han medical manuscripts based on considerations of bodily resonances-shentigan)", in: Yu S. D. 余舜德 (ed.), Tiwu ru gan: wu yu shentigan de yanjiu 體物入微: 物與身體感的研究 (Engaging things: researches on things and the experience of the body) (Taipei)

- (in prep), Chinese medicine in East Africa

Karlgren, B., Grammata Serica Recensa. The Museum of Far Eastern Antiquities, Bulletin 29 (1957) 1-332

Keegan, D. J., The "Huang-ti Nei-Ching": The Structure of the Compilation; The Significance of the Structure (Ph.D. thesis in History, University of California, Berkeley 1988)

Kovacs, J./P. U. Unschuld, Essential Subtleties on the Silver Sea: the Yin-hai jing-wei, a Chinese Classic on Ophthalmology (Berkeley 1998)

Kuriyama, S., The Expressiveness of the Body, and the Divergence of Greek and Chinese Medicine (New York 1999)

Ma, Jixing 馬繼興, Zhongyi wenxianxue 中醫文獻學 (Study of the Chinese Medical Literature) (Shanghai 1990)

- (ed.), Mawangdui gu yishu kaoshi 馬王堆古醫書考釋 (Explanation of the Ancient Medical Documents from Mawangdui) (Changsha 1992)

- /Wang Shumin 王淑民/Tao Guangzheng 陶廣正/Fan Feilun 樊飛倫 (eds), Dunhuang yiyao wenxian jijiao 敦煌醫藥文獻輯校 (Collected Collations of the Medical Texts from Dunhuang) (Nanjing 1998)

Mawangdui Hanmu boshu zhengli xiaozu 馬王堆漢墓帛書整理小組 (eds), Mawangdui Hanmu boshu 馬王堆漢墓帛書 (The Silk Documents from a Han Tomb at Mawangdui) Vol. 4 (Beijing 1985)

Meyer, F., "Théorie et pratique de l'examen des pouls dans un chapitre du rGyud-bzhi", in: T. Skorupski (ed.), Indo-Tibetan Studies: Papers in Honour and Appreciation of Professor David L. Snellgrove's Contribution to Indo-Tibetan Studies (Tring 1990) 209-256

- /Y. Parfianovitch/D. Gyurmed, Tibetan Medical Painting (London 1992)

Pfister, R., "The Jade Spring as a Source of Pleasure and Pain: the Prostatic Experience in Ancient and Medieval Medical and Daoist Texts", in: Vogel, H. U./C. Moll-Murata/Gao Xuan (eds), Studies on Ancient Chinese Scientific and Technical Texts (Zhengzhou 2006) 88-106

- forthcoming, Sexuelle Körpertechniken im alten China: seimbedürftige Männer im Umgang mit Lebens-Spenderinnen: drei Manuskripte aus Mawangdui: eine Lektüre (Books on Demand, Norderstedt, 3 vols)

Porkert, P., The Foundations of Chinese Medicine. Systems of Correspondence (Cambridge 1974)

Sivin, N., Traditional Medicine in Contemporary China. A Partial Translation of Revised Outline of Chinese Medicine (1972) with an Introductory Study on Change in Present-day and Early Medicine (Ann Arbor 1987)

- "Huang ti nei ching”, in: M. Loewe (ed.), Early Chinese Texts: a Bibliographical Guide (Berkeley 1993) 196-215

Terzioglu,A., "Die Bedeutung der chinesischen Pulslehre für die Krankheitsdiagnostik nach der persischen Handschrift Tank-suqname-i Il-Han dar Fununi-i Ulumi-i Hita'i aus dem Jahre 
1313 n. Chr.", in: C. Habrich et al. (Hrsg.), Medizinische Diagnostik in Geschichte und Gegenwart (München 1978) 71-80

Unschuld, P. U., The Classic of Difficult Issues (with Commentaries by Chinese and Japanese Authors from the Third through to the Twentieth Century) (Berkeley 1986)

Westling, Göran, Sensory-Motor Mechanisms during Precision Grip in Man (Umeå University Medical Dissertations, New Series No 171,1986)

Yang, Shouzhong (transl.), The Pulse Classic: a Translation of the Mai Jing (Boulder 1997)

Zhangjiashan 247 hao Hanmu zhujian zhengli xiaozu 張家山二四七號漢墓竹簡整理小組 (eds), Zhangjiashan Hanmu zhujian 張家山漢墓竹簡 (247 hao mu 二四七號墓) (Bamboo Strips from the Han Tomb Zhangjiashan No. 247) (Beijing 2001)

Zhao, Enjian 趙恩儉, Zhongyi maizhenxue 中醫脈診學 (Chinese Pulse Diagnostics) (Tianjin 1992)

Zhen, Yan/Cai Jingfeng, "Tibetan and Chinese Pulse Diagnostics: a Comparison - with Special Reference to Locations for Pulse-taking", in: M. Schrempf (ed.), Soundings in Tibetan Medicine: Anthropological and Historical Perspectives (Leiden 2007) 319-45

Zimmermann, F., The Jungle and the Aroma of Meats: an Ecological Theme in Hindu Medicine (Berkeley 1987)

\section{B. Premodern sources}

Bei ji qian jin yao fang 備急千金要方 (Essential Prescriptions worth a Thousand, for Urgent Need). Tang, 650/659. Sun Simiao 孫思淫. Facsimile of the Jianghu Medical School's reprint of a Northern Song edition which was reprinted in 1307 by the Meixi Shuyuan. Ziyou chubanshe (Taipei 1992)

Huangdi nei jing 黃帝內經 (Yellow Emperor's Inner Canon). Zhou to Han, 3rd c. BCE to 1st c. CE. Anon. References to Ren Yingqiu 任應秋 (ed.) Huangdi neijing zhangju suoyin 黃帝內經章句索. Renmin weisheng chubanshe (Beijing 1986)

Huangdi nei jing Su wen 黃帝內經 素問 (Yellow Emperor's Inner Canon, Basic Questions).Tang, 610. Edited by Wang Bing 王冰. Facsimile reproducing a Ming woodprint of the Song edition of 1067 by Gu Congde 顧從德. Renmin weisheng chubanshe (Beijing [1956] 1982)

Huangdi nei jing Tai su 黃帝內經 太素 (Great Purity of the Yellow Emperor's Inner Canon). Sui, 666/683. Edited by Yang Shangshan 楊上善. Renmin weisheng chubanshe (Beijing 1965)

Ling shu 靈樞 (Divine Pivot), see Huangdi nei jing 黃帝內經

Mai jing 脈經 (Canon of Sphygmology). Jin, 280 CE. Wang Shuhe 王叔和. References to Maijing jiaozhu. Annotated by Shen Yannan 沈炎南. Renmin weisheng chubanshe (Beijing 1991)

Mai jue kan wu 脈訣刊誤 (Errors in Prints of the Mai jue). Yuan. Edited by Dai Qizong 戴起宗. Renmin weisheng chubanshe (Beijing 1982)

Mawangdui manuscripts, see Ma Jixing 馬繼興 1992 and Mawangdui Hanmu boshu zhengli xiaozu 馬王堆漢墓帛書整理小組 1985 in Bibliography A.

Nan jing 難經, see Unschuld 1986

Nei jing 內經, see Huangdi nei jing 黃帝內經

Qian jin yao fang 千金翼方 (Appended Prescriptions worth a Thousand). Tang, 650/659. Sun Simiao 孫思滛. Facsimile of the Jianghu Medical School's reprint of a Northern Song edition which was reprinted in 1307 by the Meixi Shuyuan. Ziyou chubanshe (Taipei 1994)

Shi ji 史記 (Records of the Historian). Han, c. 86 BCE. Sima Qian 司馬遷. References to Shiki kaichû kôshô 史記會注考證 (Examination of the Collected Commentaries to the Records of the Historian). 1932-1934. Commented by Takigawa Kametaro 瀧川龜太郎. Toyo Bunka Gakuin (Tokyo 1934)

Su wen 素問, see Huangdi nei jing 黃帝內經 1986 or Huangdi nei jing Su wen 黃帝內經 素問 1982

Tai su 太素, see Huangdi nei jing Tai su

ZJS, see Zhangjiashan 247 hao Hanmu zhujian zhengli xiaozu 